\title{
Non-invasive ventilation corrects alveolar hypoventilation during spinal anesthesia
}

\author{
[La ventilation non effractive corrige l'bypoventilation alvéolaire traduite par l'association \\ bronchopneumopathie chronique obstructive, obésité, rachianesthésie et position de lithotomie] \\ Martine Ferrandière MD, * Eric Hazouard MD, $†$ Jean Ayoub MD PhD, $\ddagger$ Marc Laffon MD PhD, ${ }^{*}$ John Gage MD, * \\ Colette Mercier MD, ${ }^{*}$ Jacques Fusciardi MD*
}

\begin{abstract}
Purpose: To document and explain the beneficial effects of non-invasive ventilation in correcting hypoxemia and hypoventilation in severe chronic obstructive pulmonary disease, during spinal anesthesia in the lithotomy position.

Clinical features: A morbidly obese patient with severe chronic obstructive pulmonary disease underwent prostate surgery in the lithotomy position under spinal anesthesia. Hypoxemia was encountered during surgery, and a profound decrease of forced vital capacity associated with alveolar hypoventilation and ventilation/perfusion mismatching were observed. In the operating room, an M-mode sonographic study of the right diaphragm was performed, which confirmed that after spinal anesthesia and assuming the lithotomy position, there was a large decrease $(-30 \%)$ in diaphragmatic excursion. Hypoxemia and alveolar hypoventilation were successfully treated with non-invasive positive pressure ventilation.

Conclusions: Intraoperative application of non-invasive positive pressure ventilation improved diaphragmatic excursion and overall respiratory function, and reduced clinical discomfort in this patient.
\end{abstract}

Objectif : Mettre en évidence l'efficacité de la ventilation non effractive peropératoire pour corriger les effets délétères de l'association bronchopneumopathie chronique obstructive, obésité, rachianesthésie et position de lithotomie.

Eléments cliniques: Pendant une opération de la prostate réalisée sous rachianesthésie en position de lithotomie, nous avons observé : une hypoxémie liée à une majoration de l'hypoventilation alvéolaire et un effondrement de la capacité vitale forcée. Une étude échographique du diaphragme nous a permis de rattacher ces troubles à une réduction de plus de $30 \%$ de la cinétique du diaphragme. Le traitement a consisté en la mise en place peropératoire d'une ventilation non effractive au masque facial.

Conclusion : La ventilation non effractive, en restaurant la cinétique diaphragmatique, a corrigé l'hypoxémie, rétablit la capacité vitale forcée et amélioré le confort respiratoire du patient.

A N obese patient suffering from severe chronic obstructive pulmonary disease (COPD) utilizing his "hypoxic drive", underwent surgery in the lithotomy position (LP) under spinal anesthesia (SA). The respiratory consequences of both the anesthetic technique and patient positioning were studied. Impending hypoxemic respiratory failure, potentially requiring endotracheal intubation and controlled ventilation, was successfully treated with non-invasive positive-pressure ventilation (NiPPV). In accordance with the Institutional Review Board, all details of this procedure were discussed with the patient, and his written informed consent was obtained for the procedure and the publication of his personal health information.

\section{Case report}

A 58-yr-old obese man $(105 \mathrm{~kg}$, body mass index 34 $\mathrm{kg} \cdot \mathrm{m}^{-2}$ ) with severe COPD was scheduled for transurethral resection of the prostate under SA. He was a heavy smoker with a 40 -pack-yr history of cigarette usage and consequent severe respiratory disability. During four previous surgeries, supplemental oxygen administration had produced a hypoventilatory

From the Departments of Anesthesia and Critical Care, ${ }^{*}$ Pneumology; $†$ and the Division of Nuclear Medicine and Ultrasound, $\ddagger$ Regional University Hospital Center of Tours, Tours, France.

Address correspondence to: Dr. Martine Ferrandière, Réanimation Chirurgicale, Hôpital Trousseau, CHU de Tours, 37044 Tours cedex,

France. Phone: +33 2 47478551; Fax: +33 2 47474660; E-mail: ferrandiere@med.univ-tours.fi

Accepted for publication May 26, 2005.

Revision accepted November 6, 2005.

Competing interests: None declared. 
TABLE Evolution of the respiratory parameters throughout the pre- intra- and postoperative periods, and sonographic study

\begin{tabular}{|c|c|c|c|c|c|c|}
\hline \multirow[b]{2}{*}{ Evaluations points } & \multicolumn{2}{|c|}{ Preoperative evaluation } & \multicolumn{3}{|c|}{ Intraoperative evaluation } & \multirow{2}{*}{$\frac{P A C U}{P A C U}$} \\
\hline & Sitting & Lithotomy & M15 & M30 & M45 & \\
\hline Position & Sitting & Lithotomy & Lithotomy & Lithotomy & Lithotomy & $45^{\circ}$ head-up \\
\hline Anesthesia & No & No & SA $10^{\text {th }}$ dermatome & SA $10^{\text {th }}$ dermatome & SA $10^{\text {th }}$ dermatome & No residual block \\
\hline Ventilation (room air) & SV & SV & NiPPV & NiPPV & NiPPV & SV \\
\hline \multicolumn{7}{|l|}{ Respiratory evaluation } \\
\hline $\mathrm{RR}\left(\mathrm{min}^{-1}\right)$ & 24 & 20 & 24 & 22 & 20 & 20 \\
\hline $\operatorname{PEF}\left(\mathrm{L} \cdot \mathrm{min}^{-1}\right)$ & 260 & 230 & 220 & - & - & 240 \\
\hline $\mathrm{FVC}(\mathrm{L})$ & 2.6 & 1.7 & 0.9 & 2.7 & 2.8 & 1.9 \\
\hline $\mathrm{PaO}_{2}(\mathrm{mmHg})$ & 47 & 43 & 40 & 57 & 68 & 55 \\
\hline $\mathrm{PaCO}_{2}(\mathrm{mmHg})$ & 55 & 59 & 62 & 55 & 50 & 50 \\
\hline $\mathrm{SaO}_{2}(\%)$ & 81 & 77 & 75 & 90 & 93 & 83 \\
\hline$(\mathrm{Aa}) \mathrm{DO}_{2}(\mathrm{mmHg})$ & 34 & 33 & 33 & 24 & 20 & 30 \\
\hline $\mathrm{RD}[0-10]$ & 2 & 3 & 5 & 2 & 2 & 3 \\
\hline \multicolumn{7}{|l|}{ Sonographic study } \\
\hline $\mathrm{VT}(\mathrm{L})$ & 0.75 & - & 0.5 & 0.8 & - & - \\
\hline IC $(\mathrm{L})$ & 1.3 & - & 1.1 & 1.8 & - & - \\
\hline DIAq (mm) & 20 & - & 11 & 19 & - & - \\
\hline DIAd (mm) & 41 & - & 26 & 52 & - & - \\
\hline
\end{tabular}

PACU = postanesthesia care unit; SA = spinal anesthesia; M15, M30 and M45 = evaluation points 15, 30 and 45 min after spinal anesthesia; $\mathrm{SV}=$ spontaneous ventilation; $\mathrm{NiPPV}=$ non-invasive positive pressure ventilation; $\mathrm{RR}=$ respiratory rate; PEF = peak expiratory flow (can not be measured during NiPPV); FVC = forced vital capacity (measured during NiPPV on the expiratory valve); $(\mathrm{Aa}) \mathrm{DO}_{2}=$ alveoloarterial gradient in $\mathrm{O}_{2} ; \mathrm{RD}=$ respiratory discomfort (scale from 0 - no dyspnea to 10- maximal dyspnea); VT = tidal volume; IC = inspiratory capacity; DIAq = diaphragmatic inspiratory amplitude during quiet breathing; DIAd = diaphragmatic inspiratory amplitude during deep breathing (i.e., IC).

response with resultant hypoxemia: administration of $2 \mathrm{~L} \cdot \mathrm{min}^{-1} \mathrm{O}_{2}$ via nasal cannula resulted in deteriorating arterial blood gas (ABG) values : $\mathrm{pH} 7.32, \mathrm{PCO}_{2}$ $60 \mathrm{mmHg}, \mathrm{PaO}_{2} 56 \mathrm{mmHg}$, and $\mathrm{SpO}_{2} 85 \%$.

Pulmonary function tests and $\mathrm{ABG}$ were performed on the day prior to surgery to evaluate any further progression of the patient's pulmonary disease, as well as his ability to tolerate LP and SA. The results demonstrated severe COPD without a reversible component of airflow obstruction: measured total lung capacity $8.8 \mathrm{~L}$, predicted $123 \%$; measured forced vital capacity (FVC) $2.9 \mathrm{~L}$, predicted $65 \%$; measured forced expiratory flow in one second $\left(\mathrm{FEV}_{1}\right) 0.9 \mathrm{~L}$, predicted $27 \%$ (unchanged after albuterol challenge); measured $\mathrm{FEV}_{1} /$ vital capacity 0.3 , predicted $44 \%$; measured mean forced expiratory flow during the middle half of FVC $0.3 \mathrm{~L} \cdot \mathrm{sec}^{-1}$, predicted 9\%; measured carbon monoxide transfer factor/alveolar volume 3.9, predicted $103 \%$. Arterial blood gas values demonstrated pronounced respiratory insufficiency: $\mathrm{pH} 7.4 ; \mathrm{PaO}_{2}$ $47 \mathrm{mmHg}, \mathrm{PaCO}_{2} 55 \mathrm{mmHg}, \mathrm{SaO}_{2} 81 \%$. Respiratory effects of positioning and LP were assessed using a dentist's chair to mimic patient positioning during surgery. The following were measured after $15 \mathrm{~min}$ in both sitting and LP: respiratory rate, peak expiratory flow, $\mathrm{FVC}, \mathrm{ABG}$, the alveolo-arterial $\mathrm{O}_{2}$ gradient calculated as: (Aa) $\mathrm{DO}_{2}=\left[150-\left(\mathrm{PaCO}_{2} / 0.8\right)\right]-\mathrm{PaO}_{2}$, and a respiratory discomfort score, using a visual analogue scale ranging from 0 (no dyspnea) to 10 (maximal dyspnea). In the LP, room air ABG values deteriorated, and FVC was reduced (Table). However, the patient's subjective level of discomfort was nearly unchanged. Intraoperative repetition of these respiratory tests were proposed to the patient.

The patient was not premedicated prior to surgery. In addition to standard monitoring, a radial arterial catheter was inserted prior to SA. Baseline values were: blood pressure $135 / 45 \mathrm{mmHg}$, heart rate 65 beats. $\mathrm{min}^{-1}$, and $\mathrm{SpO}_{2} 82 \%$. Ringer's lactate solution $(200 \mathrm{~mL})$ was given prior to the performance of SA at the L4-5 interspace in the sitting position, using $15 \mathrm{mg}$ of $0.5 \%$ hyperbaric bupivacaine solution. The patient was positioned in LP immediately after SA. Fifteen minutes (M15) after SA, the upper level of sensory blockade was stable at the tenth thoracic dermatome (T10). The dermatomal level of sensory blockade was reevaluated every ten minutes and remained stable following LP. Pulmonary function tests and ABGs were repeated at: M15, M30 (30 min), and M45 (45 min) after SA. Results of these measurements are shown in the Table.

Spinal anesthesia was associated with a marked deterioration of FVC and ABG values (Table). The patient's subjective discomfort increased. In the 
operating room, an M-mode sonographic study of the right diaphragm (Acuson XP 128, 3.5 MHZ probe; Mountain View, CA, USA) was performed at two different times in LP: before coming in the operating theatre, and after SA (sensory blockade T10). Measurement protocols were those previously described by Ayoub et al. ${ }^{1}$ Ten cycles of quiet ventilation and three inspiratory capacities were recorded during pulmonary function test measurements. The Figure illustrates the diaphragmatic inspiratory slope at baseline (Figure, panel A), after SA and LP (Figure, panel B), and during NiPPV (Figure, panel C). After SA and LP, there was a large decrease $(-30 \%)$ in diaphragmatic excursion during inspiratory capacities.

We initiated NiPPV without oxygen supplementation at M15 to prevent the patient's impending respiratory failure, by correcting the marked deterioration in FVC and resultant hypoventilation and hypoxemia. Non-invasive positive-pressure ventilation was used in the spontaneous ventilation mode without a minimal frequency or insufflated tidal volume, using a home care pressure support ventilator (O'NYX Plus; Mallinkrodt SEFAM; Nancy, France) with a proximal expiratory valve and a full face mask (Mirage Full Face Mask Series 1; Res Med Ltd, North Ryde, Australia). Initial ventilator parameters were set at a pressure support of $8 \mathrm{~cm} \mathrm{H}_{2} \mathrm{O}$, without positive end-expiratory pressure, and then titrated as tolerated to reach the patient's preoperative tidal volume $\left(7.2 \mathrm{~mL} \cdot \mathrm{kg}^{-1}\right)$ as determined by pulmonary function tests. This was achieved using an inspiratory pressure support of 10 $\mathrm{cm} \mathrm{H}_{2} \mathrm{O}$ and a positive end-expiratory pressure of $5 \mathrm{~cm} \mathrm{H}_{2} \mathrm{O}\left(\mathrm{Pi} \max 15 \mathrm{~cm} \mathrm{H}_{2} \mathrm{O}\right.$ ). Further evaluations were done at M30, just after optimal NiPPV settings, and at M45. As shown in the Table, a sustained improvement in both oxygenation, comfort, and FVC were observed. Sonography performed during NiPPV showed a marked improvement of diaphragm kinetics (Table, Figure, panel C).

At the end of surgery, the patient was admitted to the postanesthesia care unit, and monitored in a $45^{\circ}$ head-up position as SA wore off (duration of blockade: $150 \mathrm{~min}$ ). Non-invasive positive-pressure ventilation was then withdrawn, and the patient was discharged from the postanesthesia care unit (Table). His postoperative course was uneventful.

\section{Discussion}

Over the past two decades there has been increasing emphasis in the practice of anesthesia on avoiding endotracheal intubation, either on account of the risks of airway management, or on account of the risk of prolonged mechanical ventilation in patients with

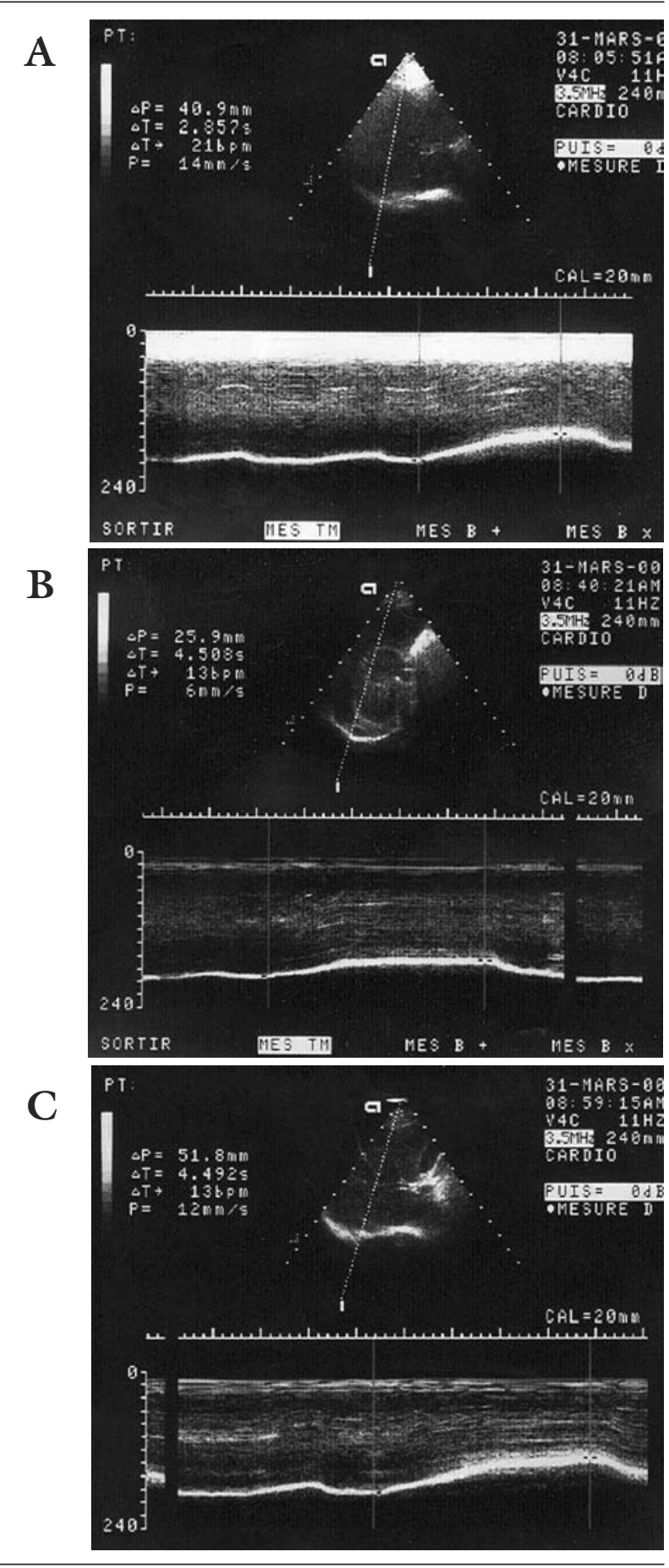

FIGURE Diaphragm sonogram during a deep inspiration. Panel A, before anesthesia, patient placed in a $45^{\circ}$-head-up position. Panel B, spinal anesthesia (tenth dermatome), patient placed in a lithotomy position and breathing spontaneously in room air. Panel C, spinal anesthesia (tenth dermatome), in lithotomy position, during non-invasive positive pressure ventilation; (up), B-mode sonogram showing the diaphragm as a bright echoic line and the M-mode marker as a dotted line; (down), M-mode sonogram showing the diaphragm motion tracing; $\mathrm{P}$, diaphragm inspiratory amplitude. 
severe chronic respiratory insufficiency. A combination of new techniques such as the laryngeal mask airway, and greater emphasis on older techniques such as regional anesthesia ${ }^{2}$ has furthered this trend. In the case under discussion here, involving a morbidly obese individual with impending respiratory failure secondary to severe chronic pulmonary disease, the decision to proceed with surgery was made only after the feasibility of regional anesthesia was thoroughly evaluated.

Transurethral prostatectomy requires a relatively low level of sensory blockade (T10) and is well managed with SA, particularly given the additional advantage of ease of early diagnosis of transurethral resection of the prostate syndrome. On the other hand, transurethral resection of the prostate is commonly performed in LP which may be associated with compromised respiratory function in some patients. The LP increases pressure on the diaphragm, leading to cephalad displacement which may influence the balance between abdominal and chest wall motion. ${ }^{3}$ Tidal volume may be decreased by $3 \%$ and vital capacity by $18 \%^{4}$ in LP, which may lead to respiratory failure in susceptible patients.

However, Reber et al. have observed that, compared with the supine position, functional residual capacity did not change significantly with LP, and lung aeration (spiral computed tomography scans of the lungs) was not significantly affected by LP. There were no changes in the amount of poorly aerated lung tissues, and the ventilation/perfusion distribution and ABG were similar. In one patient (body mass index $29 \mathrm{~kg} \cdot \mathrm{m}^{-2}$ ) who was studied in LP during epidural anesthesia, atelectasis and shunt increased. Shunt was also increased in two other patients with high body mass index placed in the supine position during epidural anesthesia. ${ }^{5}$

Some authors argue that LP favours cranial displacement of the diaphragm, which may restore the diaphragmatic length to near optimal values. ${ }^{6}$ In obese patients, this beneficial effect is negated by the increase in abdominal pressure observed after LP. Although the respiratory consequences of LP in patients with high body mass index have not been specifically studied, they appear to be associated with a reduction in diaphragmatic movement, reduction in respiratory compliance, and a restrictive ventilatory defect. ${ }^{7}$ Obesity may also induce respiratory insufficiency because of the decrease in thoraco-pulmonary compliance and functional residual capacity, and obstruction of distal airways. In addition, its association with COPD is not rare. ${ }^{8}$

The detrimental effects of SA, in our patient (Table, column 2 vs column 3), are complex. Compared with the preoperative period, the position was replicated exactly. Spinal anesthesia was stable at a low level: T10. Spinal anesthesia with a low level of blockade is ordinarily associated with preserved respiratory function. In patients with chronic respiratory insufficiency, however, neuraxial blockade may result in intercostal muscle weakness, hypoventilation, and impaired cough. ${ }^{9}$

The case we present illustrates the extent to which the association of obesity, LP and SA, may aggravate a preexisting respiratory insufficiency. Alone, neither obesity, COPD, LP or SA limited to T10 are reliably associated with impending respiratory failure, but their additive effects have not been studied, and can be hypothesized to be either additive or synergistic. Our patient suffered from severe respiratory insufficiency, with marked hypoxemia and hypercapnia at baseline. The preoperative evaluation showed that LP without anesthesia induced a measurable decrease in diaphragmatic excursion and exacerbated hypoxemia because of a worsening in restrictive and obstructive defects. A further and similar aggravation was observed after SA (Table), despite a stable low level of blockade at Tl0.

We observed that the intraoperative application of NiPPV improved diaphragmatic excursion and overall respiratory function. Non-invasive positive-pressure ventilation fully corrected hypoxemia, FVC, and reduced clinical discomfort in this patient. We chose NiPPV rather than oxygen supplementation, because our previous experience with this patient demonstrated hypoventilation in response to oxygen therapy.

The rise in $\mathrm{CO}_{2}$ levels that occur with oxygen therapy in severe COPD patients is due to a complex combination of the effects of hypoxic pulmonary vasoconstriction on venous admixture and alveolar deadspace, and the Haldane effect. ${ }^{10-13}$ The Haldane effect refers to decreased carriage of $\mathrm{CO}_{2}$ by oxyhemoglobin, and to increased $\mathrm{CO}_{2}$ release in the presence of oxygen. ${ }^{11}$ Hypoxic pulmonary vasoconstriction optimizes the distribution of ventilation/perfusion ratios, and minimizes the physiologic deadspace, improving the efficiency of $\mathrm{CO}_{2}$ exchange at low $\mathrm{FIO}_{2} \cdot{ }^{10}$ When $\mathrm{FIO}_{2}$ increases, on the other hand, hypoxic pulmonary vasoconstriction is less effective and the pulmonary vascular resistance decreases. The result is an increase in alveolar deadspace.

In our patient, NiPPV proved to be a more effective treatment of hypoxemia and hypercarbia than oxygen supplementation. The aim of NiPPV is to decrease the inspiratory effort and the work of breathing via constant pressure support. In our particular situation, positive pressure ventilation may also have counteract- 
ed the increased abdominal pressure induced by LP. The usefulness of non-invasive ventilation via a face mask in the operating room, during regional anesthesia, has not been studied previously. Only one study has used pressure support ventilation during general anesthesia with laryngeal mask airway. ${ }^{14}$ We believe that NiPPV associated with SA is a valuable alternative to general anesthesia and endotracheal intubation in borderline patients suffering from chronic lung disease who may be candidates for regional anesthesia, but who demonstrate worsening of their condition in response to oxygen therapy alone. Our sonographic study suggests that these beneficial respiratory effects may result from an improvement in diaphragmatic inspiratory excursion.

In conclusion, we report a case of impending intraoperative respiratory failure associated with hypoxemia, severe COPD, obesity, LP, and SP (tenth thoracic dermatome). We demonstrate that a possible mechanism of hypoxemia may be a diaphragmatic dysfunction, and suggest that NiPPV may be a logical and efficient method for avoiding endotracheal intubation in these patients during surgery. This hypothesis awaits further studies to establish its clinical significance.

\section{References}

1 Ayoub J, Cohendy R, Dauzat $M$, et al. Non-invasive quantification of diaphragm kinetics using M-mode sonography. Can J Anaesth 1997; 44: 739-44.

2 Hawkins JL, Koonin LM, Palmer SK, Gibbs CP. Anesthesia-related deaths during obstetric delivery in the United States, 1979-1990. Anesthesiology 1997; 86: 277-84.

3 Don HF, Craig DB, Wabba WM, Couture JG. The measurement of gas trapped in the lungs at functional residual capacity and the effects of posture. Anesthesiology 1971; 35: 582-90.

4 Case E II, Stiles JA. The effect of various surgical positions on vital capacity. Anesthesiology 1946; 7: 29-31.

5 Reber A, Bein T, Högman M, Khan ZP, Nilsson S, Hedenstierna $G$. Lung aeration and pulmonary gas exchange during lumbar epidural anaesthesia and in the lithotomy position in elderly patients. Anaesthesia 1998; 53: 854-61.

6 Giesecke AH Jr, Cale JO, Jenkins MT. The prostate, ventilation, and anesthesia. JAMA 1968; 203: 389-91.

7 Wilcox S, Vandam LD. Alas, poor Trendelenburg and his position! A critique of its uses and effectiveness. Anesth Analg 1988; 67: 574-8.

8 Benumof JL. Obesity, sleep apnea, the airway and anesthesia. Curr Opin Anaesthesiol 2004; 17: 21-30.

9 Rock P, Rich PB. Postoperative pulmonary complications. Curr Opin Anaesthesiol 2003; 16: 123-31.
10 Aubier M, Murciano D, Milic-Emili J, et al. Effects of the administration of $\mathrm{O}_{2}$ on ventilation and blood gases in patients with chronic obstructive pulmonary disease during acute respiratory failure. Am Rev Respir Dis 1980; 122: 747-54.

11 Houston JG, Morris AD, Howie CA, Reid JL, McMillan $N$. Technical report: quantitative assessment of diaphragmatic movement--a reproducible method using ultrasound. Clin Radiol 1992; 46: 405-7.

12 Lenfant C. Arterial-alveolar difference in $\mathrm{PCO}_{2}$ during air and oxygen breathing. J Appl Physiol 1966; 21 : 1356-62.

13 Hanson CW III, Marshal BE, Frasch H, Marshall C. Causes of hypercarbia with oxygen therapy in patients with chronic obstructive disease. Crit Care Med 1996; 24: 23-8.

14 Brimacombe J, Keller C, Hormann C. Pressure support ventilation versus continuous positive airway pressure with the laryngeal mask airway: a randomized crossover study of anesthetized adult patients. Anesthesiology 2000; 92: 1621-3. 